\title{
MANAGEMENT OF OPEN HEART SURGERY WITHOUT THE USE OF BLOOD
}

\author{
THE FUNGTION OF BLOOD VOLUME DETERMINATIONS
}

\author{
D.C. Funz.aYson, M.D., F.A.C.P.(c) and R.K. SuRt, M.D. $†$
}

\section{INTRODUCTION}

DURTNG THE PAST DECADE open heart surgery has become a common part of surgical practice and, with experience, increasingly safe. One of the benefits of this experience has been the reduction in the number of problems associated with bleeding and a reduction in the need for large amounts of blood. Nevertheless, although open heart surgery without the use of any blood is reported, ${ }^{\mathbf{i}-4}$ it is still uncommon.

Patients who are difficult to cross-match or who must be done in emergency situations would benefit if no transfusion were necessary and elimination of reactions to homologous blood could benefit all patients.

A further group, the Jehovah's Witnesses, whose religious beliefs preclude the use of blood or blood products would specifically benefit from a no-transfusion technique. Two such patients needing open heart surgery presented to our service and are reported in this group. Accordingly, we proceeded to evaluate blood volume criteria for patient management based on the presence of hyper-volaemia associated with the anatomical heart lesion. We hoped that haemodynamic correction with a consequent restoration of the blood volume to normal would provide the blood reserve needed for the bypass and operation.

\section{Case No. 1}

A thirty-two-year-old female, weight $44.2 \mathrm{~kg}$, and height $153 \mathrm{~cm}$, presented with dyspnoea on exertion, cyanosis, finger clubbing of several years duration, and a murmur present since childhood. Investigation revealed an atrial septal defect with a systemic to pulmonary blood flow ratio of $\mathrm{I}: 3.4$. Haematocrit was $42 \mathrm{per}$ cent. The blood volume, 4.4 litres, was 22 per cent greater than predicted (3.6 litres ). Iron storage and coagulation studies were normal.

At operation, a septum secundum was repaired through a right antero-lateral thoracotomy employing a $3.0 \mathrm{~L}$ bubble oxygenator for 20 minutes. Less than 300 $\mathrm{ml}$ of thid was infused during anaesthesia. A diuretic (Ethacrynic Acid $0.5 \mathrm{mg} / \mathrm{kg}$ ) was given and the content of the oxygenator and its tubing was returned to the patient at the end of the pump run in increments determined by the C.V.P. and the systolic, diastolic and pulse pressures.

-Assistant Professor of Anaesthesia, University of Toronto and St. Michael's Hospital.

tChief Resident, Division of Cardiovascular Surgery, St. Michael's Hospital, Present address: Asst. Professor of Cardiothoracic Surgery, Postgraduate Institute of Medical Education and Research, Chandigarh, India. 
The patient's blood volume was 4.2 litres immediately post-operatively and the haematocrit 41 per cent. The next day these values were 3.8 litres and 40 per cent respectively. The haematocrit was at its lowest level ( 35 per cent) on the third post-operative day and had risen to 42 per cent at discharge on the fourteenth postoperative day.

\section{Case No. 2}

A 36-year-old female, weight $47.3 \mathrm{~kg}$, height $157.5 \mathrm{~cm}$, presented with atrial fibrillation, marked fatigue, dyspnoea on exertion, 3-pillow orthopnoea, and swelling of the ankles. She was leading a bed-chair existence. These symptoms had progressed over a six-year period following a closed mitral commissurotomy ten years earlier.

Investigation several months pre-operatively demonstrated a calciffed stenotic mitral valve and a blood volume of 5.6 litres, 50 per cent larger than predicted.

Immediately preoperatively her heart failure improved somewhat and the blood volume was found to be 4.5 litres with a haematocrit of 38 per cent. Iron storage and coagulation studies were normal.

The patient underwent a mitral valve replacement through a right antero-lateral thoracotomy employing a fully primed 3-litre bubble oxygenator and moderate hypothermia with a bypass time of 70 minutes.

Intra-operatively, infusion of fiuid was restricted. At the time of valve replacement, a diuretic (Ethacrynic Acid $0.5 \mathrm{mg} / \mathrm{kg}$ ) was given and the blood in the extra-corporeal system (with the exception of $150 \mathrm{cc}$ remaining in the tubing) returned to the patient.

Immediately post-operatively the patient had a blood volume of 4.5 litres with a haematocrit of 38 per cent. On the first post-operative day these figures were 4.0 litres and 34 per cent respectively. Post-operatively there was left hemiparesis which resolved fully during the following two weeks. At no time during her hospital stay did the haematocrit fall below 32 per cent.

\section{Evaluation of the Patients}

Prior to operation, the blood volume, iron stores and coagulation were evaluated in these patients. Deterninations of the whole blood volume were made using 191RIHSA. The red-cell mass was then calculated from the haematocrit and values were compared with those derived from a standard height-weight nomogram. Adequate iron stores were assumed if the patient showed normal values for serum iron and total iron binding protein and a blood smear without microcytosis. Coagulation was assessed by prothrombin, partial thromboplastin, bleeding and clotting times and platelet count.

In the two cases described and in one patient with an atrial septal defect operated on subsequently, the common features were normal coagulation and iron storage studies and an increased whole blood volume with normal haematocrit, i.e., a greater-than-nomal red-cell mass. In each of these patients there was hypervolaemia associated with either a significant shunt or congestive heart failure.

A disposable bubble oxygenator (Travenol-Baxter) of a size smaller than that of the patient's blood volume was chosen and primed with $3000 \mathrm{cc}$ of a 2:1 mixture 
of Balanced Salt Solution (Normosol-R-Abbott) and 5 per cent dextrose and water. Perfusion flows ranged between 50 and $60 \mathrm{cc} / \mathrm{kg}$ body weight. Isocarbia was maintained by the use of suitable concentrations of $\mathrm{CO}_{2}$ with oxygen for ventilation of the oxygenator. The $\mathrm{pH}$ and the arterial tensions of oxygen and carbon dioxide were determined using a standard gas electrode system (Instrumentation Lab.) with suitable corrections made for alterations in body temperature. THAM was added to the oxygenator in amounts calculated to give the patient a systemic base excess of $5 \mathrm{mEq}$ /litre according to the method of Astrup. During the latter part of the bypass, diuresis was obtained by the use of a diuretic. At the end of bypass, the contents of the pump were returned to the patient in increments as noted, and in each case with a residuum of less than $300 \mathrm{ce}$ in the tubing.

There was little metabolic change in these patients immediately after the institution of bypass, except for a slight fall in serum sodium and potassium lasting about 25 minutes. The first patient, in whom THAM was omitted, had a fall in $\mathrm{pH}$ from 7.435 to 7.26 with recovery to 7.36 during this same 25 -minute period. All patients had mild to moderate hyperglycaemia with the elevations still present at the end of operation.

\section{Discussion}

A Jehovah's Witness presenting with the need for major surgery of any kind poses a number of ethical and medical problems for the physician. ${ }^{5}$ If the patient is an adult in command of his faculties, most legal systems allow him the right to refuse blood transfusion, although this right may not extend to allowing him to impose restrictions on the treatment of his minor children. The physicians involved must therefore decide whether or not they can accept the care of the patient if blood is refused. By accepting, they undertake an unusually high degree of responsibility. In terms of open heart surgery, this implies the usual meticulous standards of care with particular attention being paid to areas of surgical technique such as haemostasis and perfusion management.

Most patients ought to be able to tolerate a loss of up to 20 per cent of their circulating blood volume and, if the blood volume is maintained, losses of up to 40 per cent of their red cell mass. In these patients the whole blood volume and red cell mass were considerably above normal as a consequence of their disease. We hoped that successful surgical treatment would be followed by a reduction in the hypervolaemia associated with congestive heart failure or shunting. The amount by which this volume was reduced would give a comfortable reserve to take care of $(a)$ the operative blood loss, and, $(b)$ the increased rate of blood destruction due to decreased red blood cell survival in the initial pre-operative period until erythrocytosis had become established. However, if failure or shunting are absent in the patient, i.e., if the blood volume and red cell mass are not increased, then this "reserve" will not be present and this approach will be less effective. Furthermore, if there is a greatly accelerated rate of blood destruction due to prolonged cardiopulmonary bypass or to problems such as leakage or turbulence around a valve, then again many of the benefits of this approach will be lost. In addition, one must consider the risks of bleeding intra-operatively and post-opera- 
tively associated with the type of operation and the management of perfusion. ${ }^{*}$

\section{SUMmary}

An approach to the management of open heart surgery in Jehovah's Witnesses is described. Its success appears to depend on meticulous surgical dissection and haemostasis and on Surgery accomplished with reasonable dispatch in the presence of red cell mass and plasma volume initially larger than normal which, after haemodynamic correction, would facilitate the return of the blood volume back to normal.

\section{RÉsumÉ}

On décrit une manière daborder la chirurgie du coeur chez les témoins de Jehovah. Le succès semble dépendre d'une dissection chirurgicale et d'une hémostase méticuleuses, ainsi que d'une chirurgie pratiquée avec diligence en présence d'un volume sanguin supérieur à la normale au début et qui, après cortection hémodynamique, faciliterait le retour à la normale du volume sanguin.

\section{REFERENCES}

1. Cooley, D.A., Crawrond, E.S., Howelz, J.F., \& Beall, A. C. Open Heart Surgery In Jehovah's Witnesses. Amer. J. Cardiol, 13:779, (1964).

2. Cooley, D.A. Bloodwell, R.B., Bealt, A.C., \& Hallman, G.L. Cardiac Valve Replacement Without Blood Transfusion. Am. J. Surg. 112: 743 (Nov. 1966).

3. BanzeY, C.P., et al. Open Heart Surgery Without Blood Transfusion. J. Vase. Dis. 5 (4); 179 (Dec. 1968 ).

4. Gullub, S, at al. Electrolyte Solution in Surgical Patients Refusing Transfusion. J.A.M.A. 214 (13) : 2077, (Mar. 29, 1971 ).

5. FrtTs, W.T. \& OrEoff, M.J. Blood Transfusion and Jehovah's Witnesses. Surg. Gyn. Obst. 502; (Apr. 1959).

6. Gomes, M.M.R. \& McGoon, D.C. Bleeding Patterns After Open Heart Surgery. I, Thor. Cardiovasc. Surg. $60(1) ; 87$; (July 1970). 